\title{
Enflasyon Oranı ile Borsa İstanbul Sektör Endeks Getirileri Arasındaki İlişkinin İncelenmesi*
}

\author{
Examining the Relationship between Inflation Rate and Borsa \\ Istanbul Sector Index Returns
}

\section{Dr. Sinem Eyüboğlu - Dr. Kemal Eyüboğlu}

Başvuru Tarihi: 31.07.2017

Kabul Tarihi: 09.11.2018

\section{Öz}

Bu çalışmanin amacı 2006:01-2016:11 dönemi için enflasyon orant ile hisse senedi getirileri arasinda herhangi bir ilişki olup olmadiğının araștırılmasıdır. Çalışmada enflasyonun farklı sektörler üzerinde farklı etkileri olabileceğinden 15 Borsa İstanbul sektör endeksi kullanılmıştır. Seriler aynı seviyede durağan olmadıklarından eşbütünleşme analizi Sinır testi ile yapılmıştır. Elde edilen sonuçlar çalışmada yer alan tüm sektör endeks getirilerinin hem uzun hem de kısa dönemde TÜFE ile ilişkili olduğunu göstermiştir. İlaveten TÜFE'deki artışın 11 endeks getirisini negatif yönde etkilediği belirlenmişstir.

Anahtar Kelimeler: Enflasyon, Borsa İstanbul, Sinır Testi, ARDL Modelleri

\begin{abstract}
The purpose of this study is to investigate whether there is any relationship between inflation rate and stock returns for the period 2006: 01-2016: 11. The inflation may have different effects on the different sectors, 15 Borsa Istanbul sector indexes are used in the study. The cointegration analysis is employed by the Bound Test, since the series are not stationary at same order. The results show that the whole sector index returns are related with CPI both in long and short term. In addition, it is determined that increase in the CPI affects 11 index returns negatively.
\end{abstract}

Keywords: Inflation, Borsa Istanbul, Bound Test, ARDL Models

\begin{abstract}
Giriş
Hisse senedi piyasaları tasarruf sahipleri ile fon ihtiyacı olan taraflar arasındaki fon alış verişinin sağlandığı önemli finansal piyasalar arasında yer almaktadır. Bu süreç ile birlikte, kıt kaynakların optimum şekilde tahsis edilmesi ve böylece uzun vadeli sürdürülebilir ekonomik büyümenin temeli oluşturulmaktadır. Hisse senedi piyasaları ise bazı makroekonomik faktörlerden etkilenebilmektedir. Makroekonomik faktörler arasında, enflasyonun, hisse senedi getirilerini etkileyen en önemli faktörlerden biri olduğu düşünülmektedir. Enflasyon, bir ekonomideki malların ve hizmetlerin genel fiyat düzeyinde bir artışa neden olarak satın alma gücünde bir düşüşe neden olmaktadır.
\end{abstract}

Enflasyonun hisse senedi piyasaları üzerindeki etkisinin ise pozitif ve negatif olduğuna ilişkin 2 temel görüş vardır. Enflasyonun hisse senetlerini pozitif etkilediğine ilişkin görüş ise Fisher (1930) tarafından ortaya atılmıştır. Fisher’a göre varlık getirilerinin beklenen enflasyon oranları ile birlikte hareket etmesi gerekmektedir. Böyle bir durumda nominal hisse senedi getirileri enflasyon ile birlikte yükselmeli ve böylece yatırımcılara enflasyona karşı bir koruma sağlamalıdır (Tripathi ve Kumar, 2014, s. 648).

Fama (1981) yapmış olduğu çalı̧̧mada ise hisse senetleri ile enflasyon arasında negatif bir ilişki olduğunu tespit etmiş̧ir. Bu olumsuz ilişkiye dayanak olarak ise yüksek enflasyonun ekonomide kötüye gidişin yolunu açacağını ve bunu göz önünde bulundurarak yatırımcıların ellerindeki hisse senetlerini satmaya

\footnotetext{
Dr. Sinem Eyüboğlu, Karadeniz Teknik Üniversitesi İİB, sinemyilmaz17@hotmail.com

Dr. Kemal Eyüboğlu, Karadeniz Teknik Üniversitesi İ̈BF, keyuboglu@msn.com

* Bu çalışma, Uluslararası Ekonomi, Finans ve Yönetim Konferansı'nda sunulan çalışmanın gözden geçirilmiş ve genişletilmiş halidir.
} 
başlayacaklarını ifade etmiştir. Hisse senedi arzındaki artışın ise hisse senedi fiyatlarını düşüreceğini vurgulamıştır (Ahmed vd., 2015, s. 2).

Aynı şekilde enflasyondaki artış tüketim harcamalarını arttıracak, dolayısıyla tasarruflarda ve yatırımlarda bir düşüşe yol açacaktır. Bu durum hisse senedi ve diğer finansal varlıklara olan talebi azaltarak hisse fiyatlarında düşüşe neden olacaktır. İlaveten, enflasyondaki bir artış, artan girdi maliyetleri ile birlikte şirket karlarını olumsuz yönde etkileyecektir. Karlardaki azalış ise hisse senedi fiyatlarını düşürecektir. Başka bir bakış açısına göre ise, enflasyon oranındaki artış hisse senedi değerleme modelinde iskonto oranını arttırarak, hisse senedi fiyatlarının düşmesine neden olacaktır (Tripathi ve Kumar, 2014, s. 648).

Bu çalışmada 2006:01-2016:11 dönemi için TÜFE ile Borsa İstanbul endeksleri arasındaki ilişki araştırılmıştır. Çalışmada enflasyonun farklı sektörlerdeki etkisini görmek amaciyla 15 sektör endeksinden yararlanılmıştır. Literatürde hisse senedi piyasa endeksi ile tüketici fiyatları endeksi arasındaki ilişkiyi inceleyen çok sayıda çalışma olmasına karşın, sektör endeksleri ile tüketici fiyatları endeksi arasındaki ilişkiyi inceleyen çalışma sayısı oldukça sınırlıdır. Bu açıdan çalışmanın literatüre katkı sağlayacağı tahmin edilmektedir.

Çalışmanın bundan sonraki bölümünde enflasyon ile hisse senedi piyasaları arasındaki ilişkiyi araştıran literatürdeki çalışmalar özetlenecektir. Çalışmada kullanılan veri seti ile yöntem ise üçüncü bölümde açılanacaktır. Çalışmanın son bölümünde ise yapılan analizler sonucu elde edilen bulgular sunulacaktır.

\section{Literatür Taraması}

Enflasyon ile hisse senetleri arasındaki ilişkiler literatürde farklı ülkeler farklı dönemler için ele alınmıştır. Bu çalışmalardan; Groenewold vd. (1997) Avustralya’da 1960-1991 dönemini kapsayan çalışmasinda enflasyon ile hisse senedi getirileri arasındaki ilişkiyi incelemiş ve sonuç olarak getirilerin enflasyon ile ters yönde ilişkili olduğunu belirlemiştir. Choudry (2001) Arjantin, Şili, Meksika ve Venezüella'da farklı dönemleri inceleyerek enflasyon ile hisse senedi getirileri arasındaki ilişkiyi test etmiştir. Yapılan analizler Arjantin ve Şilide beklenen enflasyon oranının hisse senedi getirilerini pozitif yönde etkilediğini gös- termiştir. Omran ve Pointon (2001) ise 1980-1981 ile 1997-1998 dönemlerini dikkate alarak Misır'da enflasyon oranı ile hisse senedi getirileri arasındaki uzun dönem ilişkiyi test etmiş ve iki serinin hem uzun hem de kısa dönemde ilişkili olduğunu tespit etmiştir. Spyrou (2001) Yunanistan'da 1990-2000 dönemini 1990-1995 ve 1995-2000 dönemleri şeklinde ikiye ayırarak iki seri arasındaki ilişkiyi test etmiş ve 19901995 dönemi için enflasyon ile hisse senedi getirileri arasında negatif ve anlamlı bir ilişki olduğunu ortaya koymuştur. Wongbampo ve Sharma (2002) 19851996 dönemi için Malezya, Endonezya, Filipinler, Singapur ve Tayland için hisse senedi fiyatları ile enflasyonunda içinde bulunduğu bazı makroekonomik faktörler arasındaki ilişkiyi incelemiş ve beş ülkede de enflasyon ile hisse senetleri arasında negatif bir ilişki olduğunu belirlemiştir. Gunasekarage vd. (2004) 1985-2001 yılları arasını kapsayan çalışmalarında Sri Lanka’da enflasyon ile hisse senetleri arasındaki ilişkiyi incelemiş ve enflasyondaki artışın hisse senetlerini olumsuz olarak etkilediğini saptamışlardır.

Luintel ve Paudyal (2006) İngiltere'de 1955-2002 dönemini kapsayan çalışmalarında yedi sektör endeksi (madencilik, sınai, tüketici malları, hizmetler, elektrik-gaz-su, finansal kurumlar ve yatırım ortaklıkları) ile enflasyon arasındaki ilişkiyi araştırmış ve madencilik dışındaki sektörleri enflasyondaki artışın pozitif yönde etkilediğini ortaya koymuşlardır. Bhattarai ve Joshi (2009) 1995-2006 yılları için Nepal'de bazı makroekonomik faktörler ile hisse senedi piyasası arasındaki ilişkiyi incelemiş kısa dönemde enflasyondan hisse senedi piyasası doğru pozitif bir nedenselliğin olduğunu belirlemiştir. Uzun dönemde ise hisse senetlerinden enflasyona doğru bir nedenselliğin olduğunu vurgulamıştır.

Antwerpen (2010) 1928-2008 dönemi için NYSE, AMEX ve NASDAQ'da yer alan on yedi sektör endeks getirisi ile enflasyon arasındaki ilişkiyi incelemiş ve petrol-petrol ürünleri ve madencilik sektörleri getirilerinin enflasyon ile pozitif yönde ilişkili olduğunu ifade etmiştir. Saleem vd. (2013) Pakistan'da 19962011 dönemi için enflasyon ile hisse senedi piyasası getirileri arasında uzun dönem ilişki olduğunu tespit etmiştir. İlaveten iki değişken arasında ters yönlü bir ilişki olduğunu vurgulamıştır. Tripathi ve Kumar (2014) 2000-2014 yılları arasını kapsayan çalışmalarında BRICS ülkelerini ele alarak enflasyon ile hisse senedi getirileri arasındaki uzun dönemli ilişkiyi 
araştırmışlardır. Yapılan analizler sonucunda ise iki değişken arasında eşbütünleşme ilişkisi bulunmadığı belirlenmiştir. Korelasyon analizi sonuçları ise Rusyàda negatif, Hindistan ve Çin'de ise iki değişken arasında pozitif ilişki olduğunu göstermiştir. Adusei (2014) 1992-2010 yılları arasını ele alarak Ganada enflasyon ile hisse senedi getirileri arasındaki ilişkiyi incelemiş ve iki değişken arasında kısa dönemde negatif, uzun dönemde ise pozitif yönde bir ilişki olduğunu tespit etmiştir. Ahmed vd. (2015) ise Bangladeş'te 20042013 dönemi için enflasyon ile hisse senedi getirileri arasındaki ilişkiyi test etmiş ve uzun dönemde değişkenler arasında eşbütünleşme ilişkisi olduğunu ortaya koymuştur. Sulaiman vd. (2016) hisse senedi piyasaları ile enflasyon arasındaki ilişkiyi farklı dönemler için Bangladeş, Hindistan, Nepal, Pakistan ve Sri Lanka açısından ele almıştır. Çalışmadan elde edilen sonuçlar uzun dönemde borsada piyasa değerinde meydana gelen artışın enflasyonu düşürdügünü, işlem hacmindeki artışın ise enflasyonu yükselttiğini göstermiştir.

Türkiye hisse senetleri ile enflasyon arasındaki ilişkiyi araştıran çalışmalarda ise Karamustafa ve Karakaya (2004) 1995-2003 dönemi için enflasyon oranının İMKB performansı üzerindeki etkisini borsa performansı göstergesi olarak işlem hacmi, piyasa değeri, işlem miktarı, sözleşme sayısı, işlem gören şirket sayısı ve endeks değerini kullanarak araştırmışlardır. Çalışmada enflasyonun kısa ve uzun dönem ilişkilerinin birlikte ele alındığı hata düzeltme modelinde işlem hacmi ve işlem miktarı üzerinde ters yönlü etkisinin olduğu ortaya konmuştur. Ancak kısa dönem ilişkiler ele alındığında, enflasyonun işlem hacmi ile pozitif yönlü ilişkisinin olduğu, işlem miktarı üzerinde ise herhangi bir etkisinin olmadığı görülmüştür. Yılmaz vd. (2006) 1990-2003 dönemini kapsayan çalışmalarında, İMKB endeksi, tüketici fiyat endeksi, para arzı, faiz oranı, döviz kuru, dış ticaret dengesi ve sanayi üretim endeksi arasındaki ilişkiyi incelemişlerdir. Sonuç olarak hisse senedi fiyatı ile tüketici fiyat indeksi, faiz oranı ve sanayi üretim endeksi değişkenleri arasında uzun dönemli bir ilișki bulunmuştur. Horasan (2008) 1990-2007 dönemi için hisse senedi getirileri ile enflasyon arasındaki ilişkiyi incelemiş ve çalışmadan elde edilen sonuçlar Türkiye'de hisse senedi getirileri ile enflasyon arasında pozitif bir ilişki olduğunu belirlemiştir. Gençtürk (2009) 1992-2006 yılları arasını dikkate alarak makroekonomik verilerle İMKB hisse sendi fiyatları arasındaki ilişkiyi test etmiştir.
Yapılan analizler sonucu elde edilen bulgular krizlerin yaşanmadığı dönemde; tüketici fiyat endeksi hisse senetleri arasında anlamlı ve pozitif yönde bir ilişki bulunmuştur.

Özer vd. (2011) 1996-2009 dönemi için İMKB 100 endeksi ile faiz oranı, para arzı, dış ticaret dengesi, sanayi üretim endeksi, altın fiyatları, döviz kuru ve tüketici fiyat endeksi arasındaki ilişkileri araştırmışlardır. Elde edilen bulgular hisse senedi fiyatı ile tüketici fiyat indeksi, faiz oranı, para arzı, dış ticaret dengesi ve sanayi üretim endeksi değişkenleri arasında uzun dönemli bir ilişki olduğunu göstermiştir.

Yurttançıkmaz (2012) 1994-2010 dönemi için hisse senedi getirileri üzerinde enflasyonun ve döviz kurlarının etkili olup olmadığını incelemiştir. Çalışma sonucunda İMKB endeksi üzerinde enflasyonun oldukça yüksek düzeyde ve pozitif yönlü bir etkisi olduğu buna karşılık döviz kurlarının ise negatif yönlü bir etkisi olduğu belirlenmiştir.

Yüksel ve Yüksel (2013) 1997-2007 yılları arasını dikkate alarak yedi ülkede (Almanya, ABD, Arjantin, Avusturya, İsrail, Macaristan ve Türkiye) bankacılık sektörü endeksi ile tüketici fiyatları endeksi arasındaki ilişkiyi araştırmışlardır. Çalışma sonucunda sadece Arjantin'de iki değişken arasında uzun dönemli ilişki olduğu tespit edilmiştir. Çalışmada ayrıca Granger nedensellik analizi yapılmış, ABD, Avusturya ve Macaristan'da bankacılık sektörü endeksi ile tüketici fiyatları endeksi arasında nedensellik ilişkisinin olmadığı saptanmıștır.

Kendirli ve Çankaya (2016) 2009-2015 dönemi BİST Bankacilık Endeksi (XBANK) üzerinde enflasyonun ve döviz kurunun etkilerini incelemişlerdir. Yapılan analizler XBANK üzerinde enflasyonun ve döviz kurlarının \%5 anlamlılık düzeyinde anlamlı bir etkisi olmadığı ifade edilmiştir.

\section{Veri Seti ve Yöntem}

Enflasyon ile Borsa İstanbul sektör endekslerinin getirileri arasındaki ilişkinin incelendiği bu çalışmada, Tüketici Fiyatları Endeksi (TÜFE) ve 15 Borsa İstanbul endeksinden yararlanılmıştır. Çalışmada yer alan Borsa İstanbul endeksleri ise Tablo l'de gösterilmiştir. 
Tablo 1. Çalışmada Yer Alan Endeksler

\begin{tabular}{c|c|c|c|}
\hline BIST Kodu & Endeks Adı & BIST Kodu & Endeks Adı \\
\hline XUSIN & BIST Sınai & XTRZM & BIST Turizm \\
\hline XGIDA & BIST Gıda ve İçecek & XTCRT & BIST Ticaret \\
\hline XKMYA & BIST Kimya Petrol Plastik & XUMAL & BIST Mali \\
\hline XTAST & BIST Taş Toprak & XBANK & BIST Banka \\
\hline XMANA & BIST Metal Ana & XSGRT & BIST Sigorta \\
\hline XMESY & BIST Metal Eşya Makine & XFINK & BIST Finansal Kiralama \\
\hline XBLSM & BIST Bilişim & XGMYO & BIST GMYO \\
\hline XUTEK & BIST Teknoloji & & \\
\hline
\end{tabular}

Borsa endekslerinin aylık getirileri ise;

$$
R_{t}=\ln \left(\frac{P_{t}}{P_{t-1}}\right)
$$

formülü ile hesaplanmıştır. Burada $\mathrm{R}_{\mathrm{t}}$; ilgili endeksin $t$ dönemi doğal logaritmik getiri değerini, $\mathrm{P}_{\mathrm{t}}$; ilgili endeksin $t$ dönemi kapanış değerini ve $\mathrm{P}_{\mathrm{t}-1}$; ilgili endeksin t-1 dönemindeki kapanış değerini göstermektedir. TÜFE değişkenine ilişkin veriler Türkiye Cumhuriyet Merkez Bankası Elektronik Veri Dağıtım sisteminden, borsa endekslerine ilişkin veriler ise Borsa İstanbul'dan alınmıștır. İlaveten tüm değişkenlerin logaritması alınmış ve mevsimsellikten ${ }^{2}$ arındırılmıştır.

Çalışmada öncelikli olarak değerlendirmeye alınan serilerin durağan olup olmadığı test edilmiştir. $\mathrm{Bu}$ amaçla Geliştirilmiş Dickey-Fuller (ADF), PhillipsPerron (PP) ve Kwiatkowski-Philips-Schmidt-Shin (KPSS) birim kök testlerinden yararlanılmıştır. Birim kök testleri yapıldıktan sonra değişkenler arasındaki uzun dönemli ilişki incelenmiştir.

Birim kök testleri sonucunda değişkenlerin farklı seviyelerde durağan olduğu tespit edilmiş ve bu nedenle değişkenler arasında ilişkinin varlığı Pesaran vd. (2001) tarafından geliştirilen Sınır Testi yöntemi ile incelenmiştir. Sınır testi yaklaşımının uygulanması için önce kısıtlanmamış bir hata düzeltme modeli (unrestricted error correction model: UECM) kurulmuştur.

$$
\Delta \mathrm{Y}_{\mathrm{t}}=\mathrm{a}_{0}+++\alpha_{3} \mathrm{Y}_{\mathrm{t}-1}+\mathrm{a}_{4} \mathrm{X}_{\mathrm{t}-1}+\mu
$$

1 Çalışmada fiyat endekslerinden yararlanılmıştır.

2 Değișkenler Census Bureau’s X12 yöntemi kullanılarak mevsimsel etkilerden arındırılmıştır.
Yukarıdaki (2) numaralı denklemde y; ilgili Borsa İstanbul endeksini, $\mathrm{x}$; TÜFE endeksini, $\alpha_{0}$; sabit terimi, $\alpha_{1}, \alpha_{2 i}, \alpha_{3 i} ; \alpha_{4} ;$ katsayıları, $\mu$; hata terimini göstermektedir.

Denklem tahmin edildikten sonra uzun dönem ilişkinin varlığ $\mathrm{F}$ testi yapılarak belirlenir. Eğer hesaplanan F istatistik değeri alt kritik değerden küçükse seriler arasında eşbütünleşme ilişkisi olmadığı ifade edilir. Eğer hesaplanan $\mathrm{F}$ istatistik değeri alt ve üst kritik değer arasinda kaliyorsa kesin bir yorum yapılamamaktadır. Eğer hesaplanan F istatistik değeri tablo üst kritik değerini aşıyorsa seriler arasında eşbütünleşme ilişkisi olduğuna karar verilir (Abdioğlu ve Yamak, 2016, s. 84). Ayrıca ARDL modelindeki değişkenlerin istikrarı için CUSUM ve CUSUMSQ testlerinden yararlanılabilir. CUSUM ve CUSUMSQ istatistikleri $\% 5$ anlamlılık düzeyinde kritik sınırlar içerisinde ise, ARDL modelindeki katsayıların istikrarlı olduğunu ifade eden $\mathrm{H}_{0}$ hipotezi kabul edilecektir. Eğer, CUSUM grafikleri sınırların dışında kalırsa, katsayıların durağanlığını savunan $\mathrm{H}_{0}$ hipotezinin reddedilmesi gerekecektir (Akel ve Gazel, 2014, s. 36).

Eşbütünleşme ilişkisi tespit edildikten sonra değişkenler arasındaki uzun ve kısa dönem ilişkilerinin araştırılması amacıyla gecikmesi dağıtılmış otoregresif (Autoregressive Distributed Lag: ARDL) modellerin tahmin edilmesi sürecine geçilir. Burada öncelikle bağımlı ve bağımsız değişkenlerin gecikme uzunlukları AIC bilgi kriteri yardımıyla tespit edilir. Daha sonra seçilen ARDL modelinden faydalanılarak uzun dönem katsayıları ve standart hataları elde edilir. ARDL modeli (3) numaralı denklemde gösterilmiştir.

$Y_{t}=a_{0}+++\mu$ 
Son olarak değișkenler arasındaki kısa dönem ilişkisi, yine Sınır Testi yaklaşımına dayalı ARDL hata düzeltme modeli ile araştırılır. (4) numaralı denklemde ifade edilen hata düzeltme modeli yardımıyla kısa dönem katsayıları tahmin edilir.

$\Delta \mathrm{Y}_{\mathrm{t}}=\mathrm{\alpha}_{0}+++\gamma_{1} \mathrm{EC}_{\mathrm{t}-1}+\mu_{\mathrm{t}}$

Burada $\mathrm{EC}_{\mathrm{t}-1}$ terimi, hata düzeltme terimi olup; uzun dönem ilişkisinden elde edilen hata terimleri serisinin bir dönem gecikmelisini temsil etmektedir. $\mathrm{Bu}$ değişkenin negatif katsayısı, kısa dönemdeki sapmaların ne kadarının bir dönem sonra uzun dönem dengesine yaklaşacağını ifade etmektedir.

\section{Bulgular}

Çalışmada kullanılan serilere ait tanımlayıcı istatistikler Tablo 2'de gösterilmiştir. Tablodan görüleceği üzere BIST Turizm endeksi hariç diğer tüm endekslerin yatırımcılarına pozitif ortalama getiriler sağladığ belirlenmiştir. Standart sapmalar dikkate alındığında, oynaklık açısından en yüksek oynaklığa sahip endeksin BIST Finansal Kiralama, en düşük oynaklığa sahip endeksin Sınai endeksin ise olduğu belirlenmiştir. Ayrıca yer alan tüm serilerin çarpıklık katsayılarının sola çarpık, basıklık katsayıları 3'den büyük olduğu

Tablo 2. Tanımlayıcı İstatistikler

\begin{tabular}{|c|c|c|c|c|c|c|c|}
\hline Değişkenler & & 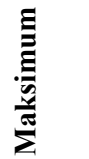 & $\stackrel{\Xi}{. \Xi}$ & 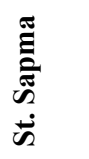 & 兰 & 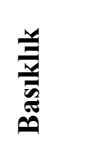 & 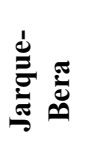 \\
\hline LTÜFE & 5,251 & 5,662 & 4,814 & 0,244 & $-0,032$ & 1,855 & $7.18^{\mathrm{b}}$ \\
\hline LXUSIN & 0,007 & 0,192 & $-0,250$ & 0,061 & $-0,978$ & 6,518 & $88.41^{\mathrm{a}}$ \\
\hline LXGIDA & 0,008 & 0,141 & $-0,209$ & 0,062 & $-0,781$ & 4,393 & $23.90^{\mathrm{a}}$ \\
\hline LXKMYA & 0,007 & 0,228 & $-0,259$ & 0,069 & $-0,570$ & 5,466 & $40.29^{\mathrm{a}}$ \\
\hline LXTAST & 0,002 & 0,123 & $-0,247$ & 0,063 & $-0,972$ & 4,510 & $33.10^{\mathrm{a}}$ \\
\hline LXMANA & 0,009 & 0,317 & $-0,341$ & 0,088 & $-0,299$ & 5,302 & $30.87^{\mathrm{a}}$ \\
\hline LXMESY & 0,009 & 0,234 & $-0,388$ & 0,086 & $-1,038$ & 6,463 & $89.01^{\mathrm{a}}$ \\
\hline LXTRZM & $-0,005$ & 0,248 & $-0,322$ & 0,089 & $-0,613$ & 4,898 & $27.86^{\mathrm{a}}$ \\
\hline LXTCRT & 0,014 & 0,162 & $-0,322$ & 0,063 & $-1,311$ & 8,941 & $230.23^{\mathrm{a}}$ \\
\hline LXUMAL & 0,003 & 0,192 & $-0,284$ & 0,079 & $-0,395$ & 4,312 & $12.79^{\mathrm{a}}$ \\
\hline LXBANK & 0,003 & 0,230 & $-0,265$ & 0,085 & $-0,189$ & 3,778 & 4.08 \\
\hline LXSGRT & 0,006 & 0,298 & $-0,410$ & 0,092 & $-1,043$ & 8,179 & $170.14^{\mathrm{a}}$ \\
\hline LXFINK & 0,005 & 0,275 & $-0,420$ & 0,095 & $-0,796$ & 6,358 & $75.41^{\mathrm{a}}$ \\
\hline LXGMYO & 0,000 & 0,192 & $-0,380$ & 0,084 & $-1,150$ & 6,786 & $107.13^{\mathrm{a}}$ \\
\hline LXUTEK & 0,012 & 0,213 & $-0,288$ & 0,083 & $-0,419$ & 4,053 & $9.88^{\mathrm{b}}$ \\
\hline LXBLSM & 0,006 & 0,260 & $-0,294$ & 0,088 & $-0,131$ & 4,085 & $6.81^{b}$ \\
\hline
\end{tabular}

a, b sırasıyla $\% 1$ ve $\% 5$ anlamlılık düzeyini göstermektedir.

için ise leptokurtik (kalın kuyruk) dağılım³ gösterdikleri tespit edilmiştir.

Çalışmada öncelikle için ADF, PP ve KPSS birim kök testleri yardımıyla serilerin durağan oldukları seviye-

3 Kalın kuyruk, dağılımların ortada dik ve uçlarda kalın kuyruk özellik gösterdiğini, diğer bir ifade ile dağılımda diğer değerlere göre ortalama civarındaki ve uçtaki değerlerin daha sık gözlendiğini ifade etmektedir. ler tespit edilmiş ve sonuçları Tablo 3'te sunulmuştur. Buna göre \%5 anlamlılık düzeyinde TÜFE’nin 1. farkında; XUSIN, XGIDA, XKMYA, XTAST, XMANA, XMESY, XTRZM, XTCRT, XUMAL, XBANK, XSGRT, XFINK, XGMYO, XUTEK ve XBLSM endeks getirilerinin ise seviyesinde durağan olduğu tespit edilmiştir. Dolayısıyla çalışmada TÜFE ile BIST endeksleri arasındaki uzun ve kısa dönemli ilişkilerin varlığı Sınır Testi yöntemi ile araştırılmıştır. 
Tablo 3. Değişkenlere Ait Birim Kök Sonuçları

\begin{tabular}{|c|c|c|c|c|c|c|}
\hline \multirow[b]{2}{*}{ Seriler } & \multicolumn{2}{|c|}{ ADF } & \multicolumn{2}{|c|}{ PP } & \multicolumn{2}{|c|}{ KPSS } \\
\hline & Sabit & $\begin{array}{c}\text { Sabit } \\
\text { \& Trend }\end{array}$ & Sabit & $\begin{array}{c}\text { Sabit } \\
\text { \& Trend }\end{array}$ & Sabit & $\begin{array}{c}\text { Sabit } \\
\text { \& Trend }\end{array}$ \\
\hline LTÜFE & -0.921 & $-3.387^{\mathrm{c}}$ & -1.022 & $-3.310^{c}$ & 1.4151 & 0.1299 \\
\hline$\Delta$ LTÜFE & $-9.934^{a}$ & $-9.955^{a}$ & $-9.928^{a}$ & $-10.150^{\mathrm{a}}$ & $0.1012^{\mathrm{a}}$ & $0.0487^{\mathrm{a}}$ \\
\hline LXUSIN & $-9.882^{a}$ & $-9.389^{\mathrm{a}}$ & $-9.136^{\mathrm{a}}$ & $-9.811^{\mathrm{a}}$ & $0.0598^{\mathrm{a}}$ & $0.0552^{\mathrm{a}}$ \\
\hline LXGIDA & $-10.636^{a}$ & $-10.008^{a}$ & $-10.080^{\mathrm{a}}$ & $-10.861^{a}$ & $0.1857^{\mathrm{a}}$ & $0.1150^{\mathrm{a}}$ \\
\hline LXKMYA & $-10.810^{\mathrm{a}}$ & $-10.888^{\mathrm{a}}$ & $-10.663^{a}$ & $-10.690^{\mathrm{a}}$ & $0.0637^{\mathrm{a}}$ & $0.0458^{\mathrm{a}}$ \\
\hline LXTAST & $-9.881^{\mathrm{a}}$ & $-9.899^{\mathrm{a}}$ & $-9.031^{\mathrm{a}}$ & $-9.011^{\mathrm{a}}$ & $0.0659^{\mathrm{a}}$ & $0.0565^{\mathrm{a}}$ \\
\hline LXMANA & $-11.083^{\mathrm{a}}$ & $-11.910^{\mathrm{a}}$ & $-9.222^{a}$ & $-9.922^{a}$ & $0.0352^{\mathrm{a}}$ & $0.0329^{\mathrm{a}}$ \\
\hline LXMESY & $-8.666^{\mathrm{a}}$ & $-8.883^{\mathrm{a}}$ & $-8.811^{\mathrm{a}}$ & $-8.122^{\mathrm{a}}$ & $0.1000^{\mathrm{a}}$ & $0.0561^{\mathrm{a}}$ \\
\hline LXTRZM & $-10.301^{a}$ & $-10.321^{\mathrm{a}}$ & $-10.368^{a}$ & $-10.388^{a}$ & $0.0672^{\mathrm{a}}$ & $0.0523^{\mathrm{a}}$ \\
\hline LXTCRT & $-10.428^{\mathrm{a}}$ & $-10.429^{a}$ & $-10.777^{a}$ & $-11.070^{\mathrm{a}}$ & $0.2024^{\mathrm{a}}$ & $0.0587^{\mathrm{a}}$ \\
\hline LXUMAL & $-8.288^{\mathrm{a}}$ & $-8.438^{\mathrm{a}}$ & $-8.233^{\mathrm{a}}$ & $-8.099^{\mathrm{a}}$ & $0.0512^{\mathrm{a}}$ & $0.0495^{\mathrm{a}}$ \\
\hline LXBANK & $-10.804^{\mathrm{a}}$ & $-10.833^{a}$ & $-10.823^{a}$ & $-10.833^{\mathrm{a}}$ & $0.0568^{\mathrm{a}}$ & $0.0459^{\mathrm{a}}$ \\
\hline LXSGRT & $-11.117^{\mathrm{a}}$ & $-11.888^{\mathrm{a}}$ & $-11.221^{\mathrm{a}}$ & $-11.772^{\mathrm{a}}$ & $0.0403^{\mathrm{a}}$ & $0.0326^{\mathrm{a}}$ \\
\hline LXFINK & $-8.888^{\mathrm{a}}$ & $-8.778^{\mathrm{a}}$ & $-8.228^{\mathrm{a}}$ & $-8.822^{\mathrm{a}}$ & $0.1106^{\mathrm{a}}$ & $0.0645^{\mathrm{a}}$ \\
\hline LXGMYO & $-9.123^{\mathrm{a}}$ & $-9.088^{\mathrm{a}}$ & $-9.248^{\mathrm{a}}$ & $-9.199^{\mathrm{a}}$ & $0.0946^{\mathrm{a}}$ & $0.0590^{\mathrm{a}}$ \\
\hline LXUTEK & $-10.134^{a}$ & $-10.833^{a}$ & $-10.331^{a}$ & $-10.073^{a}$ & $0.2268^{\mathrm{a}}$ & $0.0850^{\mathrm{a}}$ \\
\hline LXBLSM & $-9.178^{a}$ & $-9.190^{\mathrm{a}}$ & $-9.788^{a}$ & $-9.841^{\mathrm{a}}$ & $0.1863^{\mathrm{a}}$ & $0.0785^{\mathrm{a}}$ \\
\hline
\end{tabular}

\footnotetext{
a, b, c sırasılla \%1, \%5 ve \%10 anlamlılık düzeyini göstermektedir.
}

\section{Eşbütünleşme Testi}

Fiyat istikrarı, bir ekonominin istikrarlı olup olmadığını belirlemede şarttır. Fiyatlardaki sürekli artış, ekonomide belirsizlik yaratır; belirsizlik hem yerli hem de yabancı yatırımciların menkul kıymet piya- salarına olan taleplerini azaltır. Tablo 4'te değiş̧kenler arasındaki uzun dönemli ilişkinin varlığını test eden Sınır Testi sonuçları sunulmuştur. Buna göre çalışmada yer alan 15 borsa endeks getirisinin TÜFE ile eşbütünleşme ilişkisi olduğu belirlenmiştir.

Tablo 4. Sınır Testi Sonuçları

\begin{tabular}{c|c|c|c|c|c|}
\hline \multicolumn{7}{|c|}{ LTÜFE (Bağımsız Değişken) } \\
\hline Bağımlı & F istatistiği & Sonuç & Bağımlı Değişken & F & Sonuç \\
\hline LXUSIN & $13,709^{\text {a }}$ & Eşbütünleşik & LXTCRT & $39,069^{\mathrm{a}}$ & Eşbütünleşik \\
\hline LXGIDA & $17,223^{\text {a }}$ & Eşbütünleşik & LXUMAL & $37,404^{\mathrm{a}}$ & Eşbütünleşik \\
\hline LXKMYA & $36,168^{\mathrm{a}}$ & Eşbütünleşik & LXBANK & $39,910^{\mathrm{a}}$ & Eşbütünleşik \\
\hline LXTAST & $27,905^{\mathrm{a}}$ & Eşbütünleşik & LXSGRT & $31,702^{\mathrm{a}}$ & Eşbütünleşik \\
\hline LXMANA & $25,402^{\mathrm{a}}$ & Eşbütünleşik & LXFINK & $38,023^{\mathrm{a}}$ & Eşbütünleşik \\
\hline LXMESY & $25,888^{\mathrm{a}}$ & Eşbütünleşik & LXGMYO & $30,150^{\mathrm{a}}$ & Eşbütünleşik \\
\hline LXBLSM & $29,678^{\mathrm{a}}$ & Eşbütünleşik & LXUTEK & $14,168^{\mathrm{a}}$ & Eşbütünleşik \\
\hline LXTRZM & $37,484^{\mathrm{a}}$ & Eşbütünleşik & & & \\
\hline
\end{tabular}

a $\% 1$ anlamlılık düzeyini göstermektedir.

Eşbütünleşme ilişkileri tespit edildikten sonra değişkenler arasındaki uzun ve kısa dönem ilișkilerinin araştırılması amacıyla ARDL modelleri tahmin edilmiştir. Tablo 5'te hesaplanan ARDL Modeli tahmin sonuçları yer almaktadır. Buna göre tahmin sonuçla- rında otokorelasyon ve değișen varyans problemlerine rastlanılmamıştır. İlaveten ARDL modellerinde uygun model AIC kriterine göre seçilmiş ve maksimum gecikmeler 4 olarak alınmıştır. 
Tablo 5. Değişkenler için Hesaplanan ARDL Modeli Tahmin Sonuçları

\begin{tabular}{|c|c|c|c|c|c|c|c|}
\hline Değișkenler & ModeI & Katsayı & t istatistiği & Değișkenler & Model & Katsayı & t istatistiği \\
\hline LXSIN(-1) & \multirow{4}{*}{$\operatorname{ARDL}(2,1)$} & 0.137 & 1.555 & LXMANA(-1) & \multirow{4}{*}{$\operatorname{ARDL}(1,2)$} & 0.240 & $2.762^{\mathrm{a}}$ \\
\hline LXSIN(-2) & & 0.137 & 1.563 & LTUFE & & -2.521 & -1.642 \\
\hline LTUFE & & -1.471 & -1.369 & LTUFE (-1) & & 5.029 & $2.180^{\circ}$ \\
\hline LTÜFE (-1) & & 1.475 & 1.375 & LTUFE (-2) & & -2.505 & -1.629 \\
\hline $\mathrm{C}$ & & -0.007 & -0.063 & $\mathrm{c}$ & & -0.006 & -0.035 \\
\hline $\mathrm{R}^{2}=0.061 \quad \mathrm{Wl}$ & White $=1.871$ & $=0.445 \mathrm{~L}$ & $(12)=1.278$ & \multicolumn{4}{|c|}{$\mathrm{R}^{2}=0.082$ White $=1.062 \mathrm{LM}(1)=0.339 \quad \mathrm{LM}(12)=1.444$} \\
\hline Değişkenler & Model & Katsayı & t istatistiği & Değişkenler & Model & Katsayı & t istatistiği \\
\hline LXKMYA(-1) & \multirow{4}{*}{$\operatorname{ARDL}(1,1)$} & 0.093 & 1.052 & LXTAST(-1) & \multirow{4}{*}{$\operatorname{ARDL}(1,1)$} & 0.223 & $2.628^{a}$ \\
\hline LTUFE & & -1.700 & -1.381 & LTUFE & & -1.903 & $-1.780^{\circ}$ \\
\hline LTUFE (-1) & & 1.708 & 1.390 & LTUFE (-1) & & 1.91 & $1.790^{\circ}$ \\
\hline $\mathrm{C}$ & & -0.025 & -0.186 & $\mathrm{c}$ & & -0.027 & -0.238 \\
\hline \multicolumn{4}{|c|}{$\mathrm{R}^{2}=0.023$ White $=1.264$} & \multicolumn{4}{|c|}{$\mathrm{R}^{2}=0.080 \quad$ White $=0.554 \quad \mathrm{LM}(1)=0.669 \quad \mathrm{LM}(12)=1.467$} \\
\hline \multicolumn{2}{|c|}{ Değişkenter } & \multicolumn{2}{|c|}{ Mode } & \multicolumn{2}{|c|}{\begin{tabular}{c|c|} 
Katsayı & \\
\end{tabular}} & \multicolumn{2}{|c|}{ t istatistigi } \\
\hline \multicolumn{2}{|c|}{ LXMESY(-1) } & \multirow{4}{*}{\multicolumn{2}{|c|}{$\operatorname{ARDL}(1,1)$}} & 0.253 & & \multicolumn{2}{|c|}{$2.981^{a}$} \\
\hline \multicolumn{2}{|c|}{ LTUFE } & & & -2.115 & & \multicolumn{2}{|c|}{-1.443} \\
\hline \multicolumn{2}{|c|}{ LTUFE (-1) } & & & 2.136 & & \multicolumn{2}{|c|}{1.459} \\
\hline \multicolumn{2}{|c|}{$\mathrm{C}$} & & & -0.09 & & \multicolumn{2}{|c|}{-0.561} \\
\hline & & $=0.090 \quad \mathrm{~W}$ & $\bar{e}=1.077 \quad \mathrm{LN}$ & $(1)=0.283 \quad \mathrm{LM}$ & $=1,181$ & & \\
\hline Değişkenler & Model & Katsayı & t istatistiği & Değișkenler & Model & Katsayı & t istatistiği \\
\hline LXTCRT(-1) & & 0.043 & 0.492 & LXTRZM(-1) & & 0.081 & 0.934 \\
\hline LTUFE & $\operatorname{ARDL}(1,1)$ & -2.357 & $-2.119^{5}$ & LTUFE & $\operatorname{ARDL}(1,1)$ & -3.110 & $-2.002^{5}$ \\
\hline LTUFE (-1) & & 2.328 & $2.097^{\circ}$ & LTUFE (-1) & & 3.115 & $2.008^{\circ}$ \\
\hline $\mathrm{C}$ & & 0.181 & 1.495 & $\mathrm{C}$ & & -0.010 & -0.062 \\
\hline $\mathrm{R}^{2}=0.050$ Whit & $=0.611 \quad \mathrm{LM}$ & $=0.292 \quad \mathrm{~L}$ & $(12)=1.228$ & $\mathrm{R}^{2}=0.038$ Whit & $.511 \mathrm{LM}(1)$ & $0.120 \quad \mathrm{~L}$ & $(12)=0.910$ \\
\hline Değişkenler & Model & Katsayı & t istatistiği & Değişkenler & Model & Katsayı & $t$ istatistiği \\
\hline LXUMAL(-1) & & 0.087 & 1.005 & LXBANK(-1) & & 0.051 & 0.595 \\
\hline LTUFE & ARDL $(1,1)$ & -3.197 & $-2.325^{\circ}$ & LTUFE & ARDL $(1,1)$ & -3.592 & $-2.424^{\circ}$ \\
\hline LTUFE (-1) & & 3.196 & $2.327^{\circ}$ & LTUFE (-1) & & 3.584 & $2.422^{\circ}$ \\
\hline $\mathrm{C}$ & & 0.031 & 0.212 & $\mathrm{C}$ & & 0.069 & 0.430 \\
\hline $\mathrm{R}^{2}=0.052 \mathrm{Whit}$ & $0.658 \quad$ LM(1) & $0.389 \quad \mathrm{LI}$ & $2)=1.109$ & $\mathrm{R}^{2}=0.049$ Whit & .609 LM(1) & $0.466 \mathrm{LI}$ & $(12)=1.023$ \\
\hline Değişkenler & Model & Katsayı & t istatistiği & Değişkenler & Model & Katsayı & $t$ istatistiği \\
\hline LXFINK(-1) & & 0.183 & $2.191^{\circ}$ & LXGMYO(-1) & & 0.197 & 2.312 \\
\hline LTUFE & $\operatorname{ARDL}(1,1)$ & -2.272 & -1.428 & LTUFE & $\operatorname{ARDL}(1,1)$ & -3.420 & $-2.380^{\circ}$ \\
\hline LTUFE (-1) & & 2.306 & 1.451 & LTUFE (-1) & & 3.434 & $2.393^{\circ}$ \\
\hline $\mathrm{C}$ & & -0.162 & -0.938 & $\mathrm{c}$ & & -0.055 & -0.352 \\
\hline $\mathrm{R}^{2}=0.068 \quad \mathrm{Wh}$ & $=1.086 \quad \mathrm{LM}$ & $=0.22 \quad L$ & $(12)=1.282$ & $\mathrm{R}^{2}=0.088$ Whit & .458 LM(1) & $0.167 \mathrm{LI}$ & $(12)=1.002$ \\
\hline Değişkenler & Model & Katsayı & t istatistiği & Değișkenler & Model & Katsayı & t istatistiği \\
\hline$\Delta$ LXGIDA(-1) & & -0.131 & -1.499 & LXUTEK(-1) & & 0.131 & 1.483 \\
\hline$\triangle \mathrm{LXGIDA(-2)}$ & $\operatorname{ARDL}(2,0)$ & 0.172 & $1.969^{\circ}$ & LXUTEK(-2) & $\operatorname{ARDL}(2,0)$ & 0.121 & 1.381 \\
\hline$\triangle \mathrm{LTUFE}$ & & -0.014 & -0.630 & LTUFE & & 0.045 & 1.499 \\
\hline $\mathrm{C}$ & & 0.081 & 0.679 & $\mathrm{C}$ & & -0.233 & -1.451 \\
\hline $\mathrm{R}^{2}=0.235 \quad \mathrm{Wh}$ & $=0,954 \quad \mathrm{LM}$ & $=0.637$ & $(12)=1.408$ & $\mathrm{R}^{2}=0.065$ Whit & .113 LM(1) & $0.442 \mathrm{LN}$ & $12)=1,091$ \\
\hline Değişkenler & Model & Katsayı & t istatistiği & Değişkenler & Model & Katsayı & t istatistiği \\
\hline LXSGRT(-1) & ARDI $(10)$ & 0.074 & 0.857 & LXBLSM(-1) & ARDI $(10)$ & 0.157 & $1.800^{\mathrm{C}}$ \\
\hline LTUFE & AKDL $(1,0)$ & 0.016 & 0.493 & LTUFE & ARDL $(1,0)$ & 0.041 & 1.291 \\
\hline $\mathrm{C}$ & & -0.082 & -0.469 & $\mathrm{C}$ & & -0.212 & -1.260 \\
\hline $\mathrm{R}^{2}=0.037 \quad \mathrm{Whi}$ & $=0.290$ & $=0.236 \quad \mathrm{~L}$ & $(12)=0.939$ & $\mathrm{R}^{2}=0.042$ Whit &, $189 \mathrm{LM}(1)$ & $0.337 \quad \mathrm{Ll}$ & $(12)=1,585$ \\
\hline
\end{tabular}

\section{Uzun Dönemli îlişki}

ARDL modellerinin tahmin sonuçlarına göre hesaplanan uzun dönem katsayıları ise Tablo 6'da sunulmuştur. CUSUM ve CUSUMSQ grafikleri, çalışmada yer alan serilere ilişkin herhangi bir yapısal kırılma- nın olmadığını, ARDL Sınır Testine göre hesaplanan uzun dönem katsayıların istikrarlı olduğunu göstermektedir. CUSUM ve CUSUMSQ grafikleri eklerde yer almaktadır. 
Tablo 6. ARDL Modellerinden Elde Edilen Uzun Dönem Katsayıları

\begin{tabular}{|c|c|c|c|c|c|}
\hline Değişkenler & Katsayı & Değişkenler & Katsayı & Değişkenler & Katsayı \\
\hline \multicolumn{2}{|c|}{ ARDL $(2,1)$ XUSIN } & \multicolumn{2}{|c|}{ ARDL $(1,1)$ XTRZM } & \multicolumn{2}{|c|}{ ARDL $(1,1)$ XTAST } \\
\hline LTÜFE & -0.0007 & LTÜFE & 0.0055 & LTÜFE & 0.0100 \\
\hline $\mathrm{c}$ & 0.027109 & $\mathrm{c}$ & -0.0115 & $\mathrm{c}$ & -0.0358 \\
\hline Değişkenler & Katsayı & Değişkenler & Katsayı & Değişkenler & Katsayı \\
\hline \multicolumn{2}{|c|}{ ARDL $(2,0)$ XGIDA } & \multicolumn{2}{|c|}{ ARDL $(1,1)$ XTCRT } & \multicolumn{2}{|c|}{ ARDL $(1,2)$ XMANA } \\
\hline LTÜFE & -0.0148 & LTÜFE & -0.0305 & LTÜFE & 0.0034 \\
\hline c & 0.0846 & c & 0.1895 & $\mathrm{c}$ & -0.0079 \\
\hline Değişkenler & Katsayı & Değişkenler & Katsayı & Değişkenler & Katsayı \\
\hline \multicolumn{2}{|c|}{ ARDL $(1,1)$ XKMYA } & \multicolumn{2}{|c|}{ ARDL $(1,1)$ XUMAL } & \multicolumn{2}{|c|}{ ARDL $(1,1)$ XMESY } \\
\hline LTUFE & 0.0089 & LTUFE & -0.0018 & LTUFE & 0.0280 \\
\hline c & -0.0276 & $\mathrm{c}$ & 0.0348 & $\mathrm{c}$ & -0.1206 \\
\hline Değişkenler & Katsayı & Değişkenler & Katsayı & Değişkenler & Katsayı \\
\hline \multicolumn{2}{|c|}{ ARDL $(1,1)$ XFINK } & \multicolumn{2}{|c|}{ ARDL $(1,1)$ XBANK } & \multicolumn{2}{|c|}{ ARDL $(1,0)$ XBLSM } \\
\hline LTÜFE & 0.0419 & LTÜFE & -0.0089 & LTÜFE & 0.0491 \\
\hline $\mathrm{c}$ & -0.1995 & $\mathrm{c}$ & 0.0732 & $\mathrm{c}$ & -0.2519 \\
\hline Değişkenler & Katsayı & Değişkenler & Katsayı & Değişkenler & Katsayı \\
\hline \multicolumn{2}{|c|}{ ARDL $(1,1)$ XGMYO } & \multicolumn{2}{|c|}{ ARDL $(2,0)$ XUTEK } & \multicolumn{2}{|c|}{ ARDL $(1,0)$ XSGRT } \\
\hline LTUFE & 0.0184 & LTUFE & 0.0615 & LTUFE & 0.0177 \\
\hline $\mathrm{c}$ & -0.0691 & c & -0.3132 & $\mathrm{c}$ & -0.0890 \\
\hline
\end{tabular}

Buna göre elde edilen katsayılar uzun dönemde TÜFE'deki artışın 10 endeksin getirisini (XTRZM, XTAST, XGMYO, XMANA, XUTEK, XKMYA, XMESY, XSGRT, XFINK ve XBLSM) arttırdığını, 5 endeksin (XUSIN, XGIDA, XTCRT, XUMAL ve $\mathrm{XBANK}$ ) getirisini ise azalttığını göstermiştir. Ancak elde edilen bu katsayılar istatistiksel açıdan anlamsız bulunmuştur.

\section{Kısa Dönemli îlişki}

Tablo 7'de seriler arasındaki kısa dönem ilişkiyi gösteren ARDL modellerine dayalı hata düzeltme modeli sonuçları yer almaktadır.

Buna göre 15 borsa endeks getirisi ile TÜFE arasındaki kısa dönem ilişkiyi ifade eden hata düzeltme katsayılarının hepsi negatif ve istatistiksel açıdan anlamlı bulunmuştur. Bu durum TÜFE ile endeks getirileri arasında kısa dönemde ilişki olduğunu göstermektedir. Ayrıca kısa dönemde TÜFE'deki artışın 11 endeks getirisini (XUSIN, XKMYA, XMESY, XTCRT, XUMAL, XFINK, XMANA, XTAST, XTRZM, XBANK ve $X G M Y O)$ negatif yönde etkilediği belirlenmiștir. $\mathrm{Bu}$ durum iki açıdan yorumlanabilir. Birincisi mali- yet artışlarının (AOSM artışı ile) şirketlerin gelecekte sağlayacağı nakit akışlarını azaltacağı ve bunun şirket değerlerini olumsuz etkileyeceği söylenebilir. İkincisi ise enflasyon dönemlerinde yatırımciların, hisse senetlerinden faiz getiren (vadeli mevduat gibi) diğer finansal varlıklara yönelmelerinin hisse senedi fiyatlarını dolayısıyla getirilerini azaltabileceği düşünülebilir.

Hata düzeltme katsayısının negatif ve istatistiki olarak anlamlı olması, kısa dönemde meydana gelen sapmaların ne kadarının bir dönem sonrasında uzun dönem dengesine yaklaştığını göstermektedir. Tabloda yer alan katsayılar incelendiğinde tahmin değerlerinin Gıda, Ticaret, Bankacılık, Sigortacılık, Turizm, Kimya, Finansal Kiralama, Gayrimenkul, Taş ve Toprak, Metal Ana, Teknoloji, Metal Eşya Makine ve S1nai sektörleri için sırasıyla $0.961,0.957,0.948,0.925$, $0.918,0.906,0.816,0.802,0.776,0.759,0.75,0.746$ ve 0.724 olduğu görülmektedir. Buna göre kısa dönemdeki sapmaların bir dönem sonrasında sırasıyla Gıda için \%96.1, Ticaret için \%95.7, Bankacılık için \%94.8, Sigortacıllk için \%92.5, Turizm için \%91.8, Kimya için \%90.6, Finansal Kiralama için \%81.6, Gayrimenkul 
Tablo 7. ARDL Modellerine Dayalı Hata Düzeltme Modeli Sonuçları

\begin{tabular}{|c|c|c|c|c|c|c|c|}
\hline Değişsenler & XUSIN & Katsayı & $t$ istatistiği & Değişkenler & XMANA & Katsayı & t istatistiği \\
\hline$\Delta \operatorname{LXSIN}(-1)$ & \multirow[t]{3}{*}{$\operatorname{ARDL}(2,1)$} & -0.537 & -1.580 & $\triangle \mathrm{LTUFE}$ & \multirow[t]{3}{*}{ ARDL(1,2) } & -1.021 & $-2.025^{\circ}$ \\
\hline$\triangle$ LTUFE & & -1.471 & $-2.226^{\circ}$ & $\Delta$ LTUFE (-1) & & 1.005 & $2.001^{\circ}$ \\
\hline $\mathrm{EC}(-1)$ & & -0.724 & $-6.464^{a}$ & $\mathrm{EC}(-1)$ & & -0.759 & $-8.799^{a}$ \\
\hline Değişskenler & XKMYA & Katsayı & $t$ istatistiği & Değişkenler & XTAST & Katsayı & t istatistiği \\
\hline$\triangle$ LTUFE & \multirow[t]{2}{*}{ ARDL(1,I) } & -1.700 & $-2.300^{\circ}$ & $\triangle \mathrm{LTUFE}$ & \multirow[t]{2}{*}{$\operatorname{ARDL}(1,1)$} & -1.003 & $-2.892^{a}$ \\
\hline $\mathrm{EC}(-1)$ & & -0.906 & $-10.498^{a}$ & $\mathrm{EC}(-1)$ & & -0.776 & $-9.222^{a}$ \\
\hline \multicolumn{2}{|c|}{ Değişkenler } & \multicolumn{2}{|c|}{ XMESY } & \multicolumn{2}{|c|}{ Katsayı } & \multicolumn{2}{|c|}{$t$ istatistiği } \\
\hline \multicolumn{2}{|c|}{ ALTUFE } & \multirow{2}{*}{\multicolumn{2}{|c|}{ ARDL $(1,1)$}} & \multicolumn{2}{|c|}{-1.115} & \multicolumn{2}{|c|}{$-2.36 \mathrm{~T}^{\mathrm{T}}$} \\
\hline \multicolumn{2}{|c|}{ ECT(-1) } & & & \multicolumn{2}{|c|}{-0.746} & \multicolumn{2}{|c|}{$-8.881^{\alpha}$} \\
\hline Değişkenler & XTCRT & Katsayı & t istatistiği & Değişşenler & XTRZM & Katsayı & t istatistiği \\
\hline$\triangle \mathrm{LTUFE}$ & \multirow[t]{2}{*}{ ARDL(1,1) } & -1.357 & $-3.425^{\mathrm{a}}$ & $\triangle \mathrm{LTUFE}$ & \multirow{2}{*}{ ARDL(1,1) } & -1.110 & $-3.258^{a}$ \\
\hline $\mathrm{EC}(-1)$ & & -0.956 & $-10.911^{a}$ & $\mathrm{EC}(-1)$ & & -0.918 & $-10.688^{\mathrm{a}}$ \\
\hline Değişkenler & XUMAL & Katsayı & $t$ istatistiği & Değișkenler & XBANK & Katsayı & t istatistiği \\
\hline$\triangle \mathrm{LTUFE}$ & \multirow[t]{2}{*}{ ARDL(1,1) } & -1.197 & $-3.749^{a}$ & $\triangle \mathrm{LTUFE}$ & \multirow[t]{2}{*}{ ARDL(1,1) } & -1.592 & $-3.904^{a}$ \\
\hline $\mathrm{EC}(-1)$ & & -0.912 & $-10.676^{a}$ & $\mathrm{EC}(-1)$ & & -0.948 & $-11.028^{\alpha}$ \\
\hline Değişkenler & XFINK & Katsayı & $t$ istatistiği & Değișkenler & XGMYO & Katsayı & $\mathrm{t}$ istatistiği \\
\hline$\Delta$ LTUFE & \multirow[t]{2}{*}{ ARDL $(1,1)$} & -1.272 & $-2.342^{\circ}$ & $\Delta$ LXGMYO(-1) & \multirow[t]{2}{*}{ ARDL $(1,1)$} & -1.420 & $-3.815^{\mathrm{a}}$ \\
\hline $\mathrm{EC}(-1)$ & & -0.816 & $-9.829^{a}$ & $\mathrm{EC}(-1)$ & & -0.802 & $-9.585^{a}$ \\
\hline Değişkenler & XGIDA & Katsayı & $t$ istatistiği & Değişkenler & XUTEK & Katsayı & $t$ istatistiği \\
\hline$\triangle$ LXGIDA(-1) & \multirow[t]{3}{*}{ ARDL $(2,0)$} & -0.172 & $-1.978^{\circ}$ & $\Delta$ LXUTEK $(-1)$ & \multirow[t]{3}{*}{$\operatorname{ARDL}(2,0)$} & -0.120 & -1.377 \\
\hline$\overline{\triangle L T U F E}$ & & -0.278 & -0.427 & $\overline{\triangle L T U F E}$ & & -0.548 & -0.632 \\
\hline $\mathrm{EC}(-1)$ & & -0.961 & $-7.235^{\mathrm{a}}$ & $\mathrm{EC}(-1)$ & & -0.750 & $-6.576^{a}$ \\
\hline Değişkenler & XSGRT & Katsayı & t istatistiği & Değișkenler & XBLSM & Katsayı & $\mathrm{t}$ istatistiği \\
\hline ALTUFE & \multirow[t]{2}{*}{ ARDL(1,0) } & -0.617 & -0.634 & $\triangle \mathrm{LTUFE}$ & \multirow[t]{2}{*}{ ARDL(1,0) } & -0.435 & -0.469 \\
\hline $\mathrm{EC}(-1)$ & & -0.925 & $-10.689^{2}$ & $\mathrm{EC}(-1)$ & & -0.844 & $-9.679^{a}$ \\
\hline
\end{tabular}

a b ve c sırasıyla \%1, \%5 ve \%10 anlamlılık düzeyini göstermektedir.

için \%80.2, Taş ve Toprak için \%77.6, Metal Ana için \%75.9, Teknoloji için \%75, Metal Eşya Makine için \%74.6 ve son olarak Sınai sektörü için \%72.4 oranında giderilebildiğini söylemek mümkündür. Sonuçlar genel olarak uyarlanma sürecinin sektör endeksleri açısından hızlı olduğunu göstermektedir.

\section{Sonuç}

Enflasyon pek çok ülkede olduğu gibi, Türkiye için de kronik hale gelmiş sorunların başında gelmektedir. TCMB tarafından atılan adımlara rağmen Türkiye enflasyon açısından önemli bir ilerleme sağlayamamıştır. Menkul kıymet piyasalarında yatırımcıların enflasyona karşı korunmaları oldukça önem taş1maktadır. Bu çalışmada, Türkiyede 2006:01-2016:11 dönemi için enflasyon ile hisse senedi getirileri arasındaki ilişki araştırılmıştır. Bu amaçla çalışmada enflasyonun farklı sektörlerde farklı etkileri olabileceği dikkate alınarak 15 Borsa İstanbul sektör endeksi getirisi kullanılmıştır. Çalışmada TÜFE ile borsa endeks getirileri farklı seviyelerden durağan oldukları için eşbütünleşme analizi Pesaran vd.'nin (2001) geliştirmiş olduğu Sınır testi yöntemi ile yapılmıştır. Yapılan analiz sonucunda çalışmada yer alan tüm sektör endeks getirilerinin TÜFE ile uzun dönemde eşbütünleşik olduğu belirlenmiştir.

Eşbütünleşme ilişkileri tespit edildikten sonra değişkenler arasındaki uzun ve kısa dönem ilişkilerinin araştırılması amaciyla ARDL modelleri tahmin edilmiş ve uzun dönem katsayıları anlamsız bulunmuştur. Ardından hata düzeltme modelleri yardımıyla değişkenler arasındaki kısa dönemli ilişkiler araştırılmış ve tüm endeks getirilerinin TÜFE ile kısa dönemde ilişkili olduğu tespit edilmiştir. İlaveten kısa dönemde TÜFE'deki artışın 11 endeks getirisini (XUSIN, XKMYA, XMESY, XTCRT, XUMAL, XFINK, XMA- 
NA, XTAST, XTRZM, XBANK ve XGMYO) negatif yönde etkilediği belirlenmiştir. Bu durum iki şekilde yorumlanmıştır. Bunlardan ilki, enflasyonist baskı sebebiyle 11 sektör açısından gelecekteki şirket karlarının düşebileceğini dolayısıyla borsa getirilerinin de enflasyondan olumsuz etkilenebileceği saptanmıştır. Bilindiği üzere iskonto oranı enflasyonist baskı altında yükseldiğinde, nakit akışlarının bugünkü değerini düşürecek ve böylece borsa getirisini etkileyecektir. Kısaca bu sektörlerin enflasyona karşı daha hassas olduğu ifade edilebilir. Bu açıdan karar alıcıların para politikalarını düşük enflasyon ile tutarlı olacak şekilde revize etmeleri veya iyileştirmeleri gerekmektedir. İkincisi ise enflasyondaki artışın ekonomide kötüye gidişin yolunu açacağı ve dolayısıyla yatırımcıların faiz getiren (vadeli mevduat gibi) finansal varlıklara olan talebi artırarak hisse senetlerine fiyatlarını ve dolayısıyla getirilerini azaltabileceği de söylenebilir.

Aynı şekilde enflasyondaki artış tüketim harcamalarını arttıracak, dolayısıyla tasarruflarda ve yatırımlarda bir düşüşe yol açacaktır. Bu durum hisse senedi ve diğer finansal varlıklara olan talebi azaltarak hisse fiyatlarında düşüşe neden olacaktır.

Diğer taraftan XGIDA, XSGRT, XUTEK ve XBLSM sektörlerinin yatırımcısını enflasyona karşı en iyi koruyan sektörler olduğu söylenebilir. Bu açıdan elde edilen bulgular enflasyonun Borsa İstanbul üzerindeki etkilerinin görülmesi açından önemli ipuçları sunmaktadır.

Yatırımcılar açısından ise çalışmadan elde edilen sonuçlar, enflasyonun hisse senedi getirileri üzerindeki etkisini gösterdiğinden özellikle yatırım stratejilerini planlamak açısından yararlı olabilir. Örneğin, enflasyonun yükseldiği dönemlerde, yatırımcilar portföylerinde çeşitlendirme yaparak borsadaki paylarını azaltıp veya paylarını XGIDA, XSGRT, XUTEK ve XBLSM sektörlerine yönlendirip kayıplarını minimize edebilirler.

$\mathrm{Bu}$ sonuçlar, enflasyonun, menkul kıymet piyasası yatırımlarını etkileyen önemli bir makroekonomik değişken olduğunu göstermektedir. İlerleyen çalışmalarda farklı makroekonomik faktörlerin sektör endeksleri üzerindeki etkileri incelenerek literatüre katkı sağlanabilir.

\section{Kaynakça}

Abdioğlu, Z., Yamak, R. (2016). Türk İmalat Sanayinde Sektörler Bazında Verimlilik Çıktı İlişsisi: Verdoorn Yasası. Uluslararası Ekonomik Araștırmalar Dergisi, 2 (2), 81-91.

Adusei, M. (2014). The Inflation-Stock Market Returns Nexus: Evidence from the Ghana Stock Exchange. Journal of Economics and International Finance, 6 (2), 38-46.

Ahmed, S. F., Islam, K.M. Z., Khan, Md. R. (2015). Relationship between Inflation and Stock Market Returns: Evidence from Bangladesh. Daffodil International University Journal of Business and Economics, 9(1), 1-12

Akel, V., Gazel, S. (2014). Döviz Kurları İle BIST Sanayi Endeksi Arasındaki Eşbütünleşme İlişkisi: Bir ARDL Sınır Testi Yaklaşımı. Erciyes Üniversitesi İktisadi ve İdari Bilimler Fakültesi Dergisi, (44), 23-41.

Antwerpen, D. V. (2010). Hedging Inflation by Selecting Stock Industries. Thesis Erasmus School of Economics, 1-30.

Bhattarai, C., Joshi, N.K. (2009). Dynamic Relationship among the Stock Market and the Macroeconomic Factors: Evidence from Nepal. South Asia Economic Journal, 10 (2), 451-469.

Choudhry, T. (2001). Inflation and Rates of Return on Stocks: Evidence from High Inflation Countries. Journal of International Financial Markets, 11, 75-96.

Dickey, D.A., Fuller, W.A. (1981), "Likelihood Ratio Statistics for Autoregressive Time Series with a Unit Root", Econometrica, 49 (4), 1057-1072.

Fama, E. (1981). Stock Returns, Real Activity, Inflation and Money. American Economic Review, 71, 545565 .

Fisher, I. (1930). The Theory of Interest. New York: Macmillan. 
Gençtürk, M. (2009). Finansal Kriz Dönemlerinde Makroekonomik Faktörlerin Hisse Senedi Fiyatlarına Etkisi. Süleyman Demirel Üniversitesi İktisadi ve İdari Bilimler Fakültesi Dergisi, 14 (1), 127-136.

Groenewold, N., O’Rourke, G., Stephen T. (1997). Stock Returns and Inflation: A Macro Analysis. Applied Financial Economics, 7 (2), 127-136.

Gunasekarage, A., Pisedtasalasai, A., Power, D.M. (2004). Macroeconomic Influence on the Stock Market: Evidence from an Emerging Market in South Asia. Journal of Emerging Market Finance, 3 (3), 285-304.

Horasan, M. (2008). Enflasyonun Hisse Senedi Getirilerine Etkisi: İMKB 100 Endeksi Üzerine Bir Uygulama. Atatürk Üniversitesi İktisadi ve İdari Bilimler Dergisi, 427-435.

Karamustafa, O., Karakaya, A. (2004). Enflasyonun Borsa Performansı Üzerindeki Etkisi. Kocaeli Üniversitesi Sosyal Bilimler Enstitüsü Dergisi, (7) 1, 2335.

Kendirli, S., Çankaya, M. (2016). Döviz Kuru ve Enflasyonun BIST Banka Endeksi Üzerindeki Etkisi. MANAS Sosyal Araştırmalar Dergisi, 5 (3), 215227.

Kwiatkowski, D., Phillips, P. C. B., Schmidt, P., Shin, Y. (1992). Testing the Null Hypothesis of Stationarity against the Alternative of a Unit Root, How Sure are We that Economic Time Series have a Unit Root?, Journal of Econometrics, 54, 159-178.

Luintel, K. B., Krishna P. (2006). Are Common Stocks a Hedge Against Inflation?. The Journal of Financial Research, 29 (1), 1-19.

Omran, M., Pointon, J. (2001). Does the Inflation Rate Affect the Performance of the Stock Market?. The Case of Egypt. Emerging Markets Review, 2, 263279.

Özer, A. Kaya, A., Özer, N. (2011). Hisse Senedi Fiyatları ile Makroekonomik Değişkenlerin Etkileşimi. Dokuz Eylül Üniversitesi İktisadi ve İdari Bilimler Fakültesi Dergisi, 26 (1) , 163-182.
Pesaran, M., Shin, Y., Smith, R. J. (2001). Bounds Testing Approaches to the Analysis of Level Relationships. Journal of Applied Econometrics, 16, 289-326.

Phillips, P. C., Perron, P. (1988). Testing for a Unit Root in Time Series Regression. Biometrika, 75 (2), 335 346.

Saleem, F., Zafar, L., Rafique, B. (2013). Long Run Relationship between Inflation and Stock Return: Evidence from Pakistan. Social Sciences and Humanities, 4(2), 1-9.

Spyrou S. I. (2001). Stock Returns and Inflation: Evidence From an Emerging Market. Applied Economics Letters, 8, 447-50.

Sulaiman, I., Arshed, N., Hassan, M. S. (2016). Stock Market Development, Can It Help Reduce Inflation in SAARC Countries. Journal of Accounting, Finance and Economics, 6 (1), 101-110.

Tripathi, V., Kumar, A.(2014). Relationship between Inflation and Stock Returns - Evidence from BRICS Markets Using Panel Cointegration Test. International Journal of Accounting and Financial Reporting, 4 (2), 647-658.

Wongbampo, P., Sharma, S.C. (2002). Stock Market and Macroeconomic Fundamental Dynamic Interactions: ASEAN-5 Countries. Journal of Asian Economics, 13, 27-51.

Yılmaz, Ö., Güngör, B., ve Kaya, V. (2006). Hisse Senedi Fiyatları ve Makro Ekonomik Değişkenler Arasında Eşbütünleşme ve Nedensellik. İMKB Dergisi, 9 (34), 1-16.

Yurttançıkmaz, Z. Ç. (2012). Döviz Kuru ve Enflasyonun Hisse Senedi Getirileri Üzerindeki Etkisi. EKEV Akademi Dergisi, 16 (51), 393-410.

Yüksel, A., Yüksel, A. (2013). Bankacılık Sektörü Hisse Senedi Endeksi İle Enflasyon Arasındaki İlişki Yedi Ülke Örneği. Yönetim ve Ekonomi, 20 (2), 37 50. 